\title{
Demographic Characteristics and Prevalence of Mandibular Condylar Fractures at a Tertiary Care Dental Hospital in Dhaka City
}

\author{
Mohammad Wahidul Islam¹, Mohiuddin Ahmed ${ }^{2}$, AFM Shahidur Rahman ${ }^{3}$ \\ ${ }^{1}$ Assistant Professor, Oral and Maxillofacial Surgery Department, Dhaka Medical College and Hospital, \\ Dhaka, Bangladesh; ${ }^{2}$ Principal, Sapporo Dental College, Dhaka, Bangladesh; ${ }^{3}$ Associate \\ Professor \& Head, Department of Oral and Maxillofacial Surgery, Shaheed \\ Suhrawardy Medical College, Dhaka, Bangladesh
}

[Received: January 2015; Revised: March 2015; Accepted: June 2015; Published: July 2015]

\begin{abstract}
Background: Mandibular condylar fracture is a critical condition. Objectives: The purpose of the study was to see the demographic characteristics and prevalence of mandibular condylar fractures. Methodology: This cross-sectional study was conducted in the Department of Oral and Maxillofacial Surgery of Dhaka Dental College and Hospital from January 2009 to September 2010 for a period of one year and nine months. All the patients presented with mandibular condylar fractures at any age with both sexes were included as study population. Details demographic characteristics and the rate of occurrence were recorded. Result: A total number of 26 patients were included in this study. Majority of the patients were male $(88.5 \%)$ and age belongs to 21 to 30 years (38.5\%). Road traffic accident (46.2\%) was the main cause and unilateral fractures were more frequent. The prevalence of mandibular condylar fracture was $14.9 \%$. Conclusion: Mandibular condylar fracture is most commonly occurred in male with a low prevalence. [Journal of National Institute of Neurosciences Bangladesh, 2015;1(2): 50-52]
\end{abstract}

Keywords: Mandibular condylar fractures; prevalence; demographic characteristics

Correspondence: Dr. Mohammad Wahidul Islam, Assistant Professor, Oral and Maxillofacial Surgery Department, Dhaka Medical College and Hospital, Mirpur-14, Dhaka, Bangladesh; Email: wahidul.prince@gmail.com; Cell no.: +8801711152706

Conflict of interest: There is no conflict of interest to any of the authors of this article.

Funding agency: This study was not funded by any authority.

Contribution to authors: MWI \& MA were contributed from protocol preparation up to report writing. MWI has prepared the manuscript and AFMSR have revised the manuscript.

How to cite this article: Islam MW, Ahmed M, Rahman AFMS. Prevalence of Mandibular Condylar Fractures at a Tertiary Care Dental Hospital in Dhaka City. J Natl Inst Neurosci Bangladesh, 2015;1(2): 50-52

\section{Introduction}

Injuries of maxillofacial complex represent one of the most important health problems worldwide ${ }^{1}$. Particular interest is created by high incidence and diversity of facial lesions. Moreover, maxillofacial fractures are often associated with severe morbidity, loss of function, disfigurement and significant financial $\operatorname{cost}^{2}$. In the past 50 years the incidence of mandibular fractures are increasing which is possibly related to changes in reporting of data; however, more likely is a result of advancement in the field of diagnostic imaging that allow a more accurate detection of these fractures.

In any event fracture involving the condylar process are by no means uncommon and probably make up between one quarter and one third of all mandibular fractures ${ }^{2}$. Mandibular condylar fractures are common in maxillofacials trauma accounting for 20 to $52 \%$ of all mandibular fractures ${ }^{3}$. According to Kelly ${ }^{4}$ the most common unilateral fracture is of the condyle and the most common bilateral fractures is of the condylar heads. According to Villarrel et $\mathrm{al}^{5}$ these are the most controversial fracture regarding diagnosis and management. Most of the condylar fractures are not caused by direct trauma which follows indirect forces transmitted to the condyle from a blow elsewhere. Therefore, condylar fractures are commonly missed ${ }^{6-7}$. There are two types of fractures intracapsular and extracapsular, but for practical purposes the anatomical 
level of the fractures is divided into three sites which are the condylar head (intracapsular), the condylar neck (extracapsular) and the subcondylar region ${ }^{6,8-11}$. The fracture is classified as undisplaced, deviated, displaced with medial and lateral overlap or complete separation and dislocated out site the glenoid fossa. Lindhal ${ }^{12}$ also classified head fractures into horizontal, vertical and compression types ${ }^{8}$. Condylar head dislocation occurs more frequent in children. As there is no systematic study in Bangladesh about prevalence of condylar fractures and their management, this would help us in getting more information about demographic characteristics and etiology of condylar fractures in the perspective of Bangladesh. Therefore the present study was undertaken to see the demographic characteristics and prevalence of mandibular condylar fractures.

\section{Methodology}

This was a cross sectional study conducted in in Department of Oral and Maxillofacial Surgery at Dhaka Dental College and Hospital from January 2009 to September 2010 for a period of one year and nine months. Patients who were admitted into hospital and were attended to outpatient department with mandibular fractures irrespective of age and sex were selected as study population. A standardized structured data collection instrument was used to collect necessary information of the patients who were examined in Oral and Maxillofacial Surgery Department of Dhaka Dental College and Hospital, Dhaka, and these included histories of the patient a questionnaire use for demographic data and clinical history and clinical examination, radiological findings which were recorded in data collection sheet. Data were analyzed by SPSS Ver. 15 statistical software.

\section{Results}

Majority of the patient were in the age group of 21 to 30 years which was $10(38.5 \%)$ cases followed by 11 to 20 years and 31 to 40 years which were $7(26.9 \%)$ cases and $4(15.4 \%)$ cases respectively (Table 1$)$

Table 1: Age distribution of the patients $(n=26)$

\begin{tabular}{lcc}
\hline Age Group & Frequency & Percentage \\
\hline 0 to 10 years & 3 & 11.5 \\
11 to 20 years & 7 & 26.9 \\
21 to 30 years & 10 & 38.5 \\
31 to 40 years & 4 & 15.4 \\
41 to 50 years & 1 & 3.8 \\
>50 years & 1 & 3.8 \\
Total & $\mathbf{2 6}$ & $\mathbf{1 0 0 . 0}$ \\
\hline
\end{tabular}

Male was predominant than female which was $23(88.5 \%)$ cases and $3(11.5 \%)$ cases respectively (Table 2).

Table 2: Sex Distribution of the patients $(\mathrm{n}=26)$

\begin{tabular}{lcc}
\hline Sex & Frequency & Percentage \\
\hline Male & 23 & 88.5 \\
Female & 3 & 11.5 \\
Total & $\mathbf{2 6}$ & $\mathbf{1 0 0 . 0}$ \\
\hline
\end{tabular}

Regarding the causes of mandibular condylar fracture road traffic accident was the most common which was $12(46.1 \%)$ cases followed by physical assault and fall from height which were $8(30.8 \%)$ cases and $6(23.1 \%)$ cases respectively (Table 3 ).

Table 3: Causes of Mandibular Condylar Fracture among the Study Population $(\mathrm{n}=26)$

\begin{tabular}{lcc}
\hline Causes of Fractures & Frequency & Percentage \\
\hline Fall from Height & 6 & 23.1 \\
Road Traffic Accident & 12 & 46.1 \\
Physical Assault & 8 & 30.8 \\
Total & $\mathbf{2 6}$ & $\mathbf{1 0 0 . 0}$ \\
\hline
\end{tabular}

The prevalence of mandibular condylar fracture was $26(14.9 \%)$ cases; however, mandibular facture without the condylar fracture was $148(85.1 \%)$ cases (Table 4$)$.

Table 4: Prevalence of Mandibular Condylar Fractures $(\mathrm{n}=26)$

\begin{tabular}{lcc}
\hline Mandibular Fractures & Frequency & Percentage \\
\hline With Condylar fractures & 26 & 14.9 \\
Without Condylar fractures & 148 & 85.1 \\
Total & $\mathbf{1 7 4}$ & $\mathbf{1 0 0 . 0}$ \\
\hline
\end{tabular}

\section{Discussion}

Bangladesh is a developing country with 150 million people and road traffic system is very poor. Thus the prevalence of mandibular condylar fractures is significantly high due to road traffic accident. Epidemiological survey of condylar fractures in Bangladesh is not yet been done; however, several cross-sectional study on jaw fractures have been done. This cross-sectional study was carried out in the Department of Oral and Maxillofacial Surgery from January 2009 to September 2010 with a sample size of 26 patients presented with condylar fractures of mandible. The current study investigated the demographic pattern and causes of condylar fractures of mandible. In this study it was found that highest 
percentage of patients was in the age ranges of 21-30 years $(38.5 \%)$ followed by in the age group of 11-20 years $(26.9 \%)$. The finding is almost similar with other studies ${ }^{15-16}$. Sawazaki ${ }^{15}$ was performed a case series of 263 patients of condylar fractures and among the study population the mean age was 28.4 years. Ahmed $^{16}$ treated 230 patients with maxillofacial trauma and 20-29 years of age sustained the most maxillofacial fractures. In this study condylar fractures patients are mostly male $(88.5 \%)$. Male and female ratio is $7.7: 1$. Other studies are also showed that majority of the patients are male; however, there was dissimilarity in the ratio of male and female. Sawazaki ${ }^{15}$ found 3.1:1 ratio of ale and female.

In this study road traffic accident is the leading etiological factor $(46.2 \%)$ followed by physical assault $(30.8 \%)$ and fall from height $(23.1 \%)$. Road traffic accident is the commonest cause of condylar fracture in other studies as well. It is due to overcrowding, unsecured road, violation of traffic rules and unskilled driving. The most common cause of condylar fracture is road traffic accident (57.8\%). In this study prevalence of condylar fracture among all mandibular fractures were $14.9 \%$. Rahman ${ }^{17}$ has found that condylar fractures among all mandibular fractures were $14 \%$.

\section{Conclusion}

In conclusion mandibular condylar fracture is most commonly found in younger age group. Male is predominant. Furthermore road traffic accident is the main cause fracture.

\section{References}

1. Brasileiro BA, Passeri LA. Epidemiological analysis of maxillofacial fractures. Oral Surgery, Oral Medicine, Oral pathology and Endodontology 2006;102(1):28-34

2. Kademani D, Rombach DM, Qunin PD. Trauma to the temporoman- dibular joint region. In: R.J. Fonsecaed. Oral and maxillofacial trauma.1.3rd.U.S.A: Elsevier.2005;523-562

3. Biglioli F, Colleli G. Transmasseter approach of condylar fractures by mini-retromandibular access. Am J Oral Maxillofac Sur 2009;67:2418-2424

4. Killey. Fractures of the condylar region. In: P. Banks ed. KIlley's fractures of mandible.4th.Bombay: Varghese publishing house. 1991;94-105

5. Villareal PM, Monje F, Junquera LM, Mateo J, Morillo AJ, Gonzalez C. Mandibular condylar fractures: determinants of treatment and outcome. J Oral Maxillofac Surg 2004;62:155-163

6. Silvennoinen U, Lizuka T, Lidqvist C, Oikarinen K. Different pattern of condylar fractures; an analysis of 382 patients in a 3 years period. J Oral Maxillofac Sur 1992;50: 1032-1037

7. Pereira MD, Marques A, Ishizuka M, Keira SM, Brenda E, Wolosker AB. Surgical treatment of the fractured and dislocated condylar process of mandible. J Cranio Maxillofac Sur 1995;23: 369-376

8. Lindal L, Hollender L. Condylar fractures of mandible. Internat J Oral Sur 1997;6:153-156

9. Laskin DM. Establishing new standards. J Oral Maxillofac Surg 1991;49:1141

10. Zhang X, Obeid G. A comparative study of the treatment of unilateral fractured and dislocated mandibular condyles in the rabbit. J Oral Maxillofac Surg 1991;49:1181-1190

11. Newman L. A clinical evaluation of the long term outcome of patients treated for bilateral fracture of the mandibular condyles. British J Oral Maxillofac Surg 1998;36:176-179

12. Zachariades N., Mezitis M., Mourouzis C., Papadakis D. and Spanou A. Fractures of the mandibular condyle. Journal of Cranio-Maxillofacial Surgery. 2006; 34( Issue 7):421-432

13. Yasuoka T. and Oka N. Histomorphic study of trabecular bone remodeling during condylar fracture healing in the following period. J Oral Maxillofac Surg 1991;49:981-988

14. Valiati R.,Ibrahim D., Abreu M.E.R., Heitz C., Oliveria R.B. Pagnoncelli R.M., Silvia D.N. The treatment of condylar fractures: to open or not to open? A critical review of this controversy. Internat $\mathrm{J}$ Med Sci 2008;5(6):313-318

15. Sawazaki R., Junior S.M.L., Asprino L. Incidence and pattern of mandibular condyle fractures. Am J Oral Maxillofac Sur 2009;64:1016 16. Ahmed H.E.A., Jaber M.A., Fanas S.H.A., Karas M. The pattern of maxillofacial fractures in Sharjah, United Arab Emirates: A Review of 230 cases. Oral Sur, Oral Med, Oral Path Endodontol 2004;98(2):166-170

17. Rahman AFMS. Study on jaw fractures in maxillofacial trauma patients. [FCPS Dissertation], BCPS, 2008

18. MacLennan WD. Fractures of mandibular condylar process. British J Oral Maxillofacial Sur 1969;7:31-39 